JURNAL SEKRETARIS DAN ADMINISTRA SI BISNIS

Journal homepage http /ljurnal asmtbac id/index php/jsab

"Handling Incoming Mail Using Dropbox Applications For Effective Internal Communication In The Digital Age”

\title{
Penanganan Surat Masuk Dengan Aplikasi Dropbox Untuk Efektifivitas Komunikasi Internal di Era Digital
}

${ }^{1)}$ Tengku Sitti Rochmah; ${ }^{2}$ Chandra Hendriyani, ${ }^{3)}$ Shafira Ramadhanty

${ }^{1,2,3)}$ Akademi Sekretari dan Manajemen Taruna Bakti

${ }^{1)}$ verasittirochmah@yahoo.com; ${ }^{2}$ chandrahendriyani@yahoo.com; ${ }^{3)}$ shafirazahra07@gmail.com

\begin{tabular}{l} 
Article info \\
\hline Article history: \\
Received $22^{\text {nd }}$ December 2020 \\
Received in revised form $7^{\text {th }}$ January \\
2020 \\
Accepted $06^{\text {th }}$ February 2020 \\
\hline Keywords: \\
Inbox, \\
Dropbox, \\
Cloud Computing
\end{tabular}

\begin{abstract}
The rapid development of technology in the digital era is driving changes in the way things work from manual to computerized. Changing the platform to computerization in administration is very helpful for companies, one of which is in cloud computing-based data storage through the use of the Dropbox application. The approved technology will provide benefits consisting of costs incurred, approved operational, and optimization of resources 6 hpvzgfor the company.
\end{abstract}

The purpose of this research is to study the process of implementing incoming mail and distributing mail using the Dropbox application and the benefits that come after distributing mail using the Dropdox application. The research method used is descriptive discussion. Data collection techniques carried out by observation, interviews with branch unit secretaries, and literature studies from books, journals, and documents relating to the discussion of research.

The results of the study show that research and distribution of incoming mails using Dropbox conducted by BPJS Employment Cimahi in the digital era is currently facilitating work processes and internal communication between employees and encouraging new goals for companies that can be used quickly. 


\section{Pendahuluan}

Pesatnya perkembangan teknologi saat ini berpengaruh besar terhadap kemajuan dunia bisnis. Kemajuan teknologi tersebut ditandai dengan adanya perubahan revolusi industri 4.0 atau dikenal dengan era digital. Revolusi industri 4.0 tersebut mendorong terjadinya perubahan cara kerja mulai dari manual menjadi komputerisasi. Digitalisasi menjadi suatu hal yang tidak dapat dihindari dan semua jenis organisasi harus memiliki kegesitan dalam merespon perubahan agar dapat terus bersaing untuk kelangsungan organisasi. Perubahan platform ke digital diimplementasikan ke dalam semua proses yang terdapat di organisasi. Teknologi diyakini akan memberi manfaat berupa efisiensi biaya, fleksibilitas operasional, dan optimalisasi sumber daya bagi perusahaan. Oleh karena itu, untuk mendorong pertumbuhan kinerja perusahaan yang baik, maka konektivitas menjadi platform untuk menghilangkan keterbatasan dan memenangkan persaingan melalui penerapan teknologi yang berbasis pelanggan. IT muncul melengkapi dan di\% ke dalam strategi bisnis, organisasi desain, struktur, dan kompetensi untuk mencapai bisnis yang berkelanjutan (Barua \& Mukhopadhyay dalam Sambamurty, 2003).

Salah satunya merubah platform administrasi dari konvensional ke digital administrasi. Digital administrasi dikenal dengan e-administration. E-administration merupakan mekanisme yang mengubah aktivitas tradisional dengan proses kertas menjadi proses elektronik(Radu \& Polkowski, 2014). Salah satu kegiatan administrasi adalah kegiatan surat menyurat. Surat merupakan alat komunikasi tertulis yang berasal dari satu pihak dan ditujukan kepada pihak lain untuk menyampaikan warta (Bartos, 2005) dimana dalam organisasi komunikasi terdiri atas komunikasi internal dan eksternal.

Surat merupakan bentuk komunikasi tertulis yang digunakan dalam internal maupun eksternal. Mengurus dan mengendalikan surat adalah kegiatan mengelola surat masuk dan surat keluar yang meliputi kegiatan menerima, mencatat, mengarahkan, mendistribusikan, memproses lebih lanjut, dan menyimpan surat sesuai dengan prosedur yang berlaku (Sedarmayanti, 2014). Proses pengelolaan surat menyurat merupakan hal yang penting dan perlu dilakukan dengan segera agar korespondensi berjalan dengan baik sehingga informasi dapat cepat tersampaikan dan operasional perusahaan tidak akan terganggu.

Penerapan teknologi dengan e-administration sangat membantu bagi perusahaan dalam penyimpanan data yaitu melalui penggunaan aplikasi Dropbox. Aplikasi pengelolaan dokumen yang dikembangkan dapat digunakan untuk mengatur dan mengelola surat-surat ataupun dokumendokumen penting agar dokumen tersebut mudah untuk dicari dan ditemukan kembali, bermanfaat dalam mengefektifkan dan mengefisienkan proses bisnis, dapat menemukan informasi yang 
dibutuhkan dengan cepat, memudahkan dalam distribusi, penelusuran disposisi, terjaminnya pengiriman dan dapat membantu proses menjadi lebih cepat, lebih baik dan murah (Suryana, 2012). Aplikasi ini juga memudahkan proses komunikasi data antar bagian serta pembuatan laporan yang selalu di up date dan bisa dilihat berdasarkan laporan bulanan maupun tahunan. Dropbox merupakan salah satunya dari sebagian besar layanan sinkronisasi file cloud yang digunakan oleh akademisi dan bisnis (de Bruin \& Floridi, 2017). Dropbox juga dapat membantu mengelola administrasi dalam sebuah perusahaan salah satunya untuk mengurus dan mengelola surat. Cloud computing banyak digunakan selain untuk efisiensi juga untuk kecepaatan mengakses informasi yang dapat diunggah serta dibaca kapan dan dimana saja. (Caviglione et.al., 2016).

Salah satu perusahan yang telah mengimplementasikan penggunaan dropbox adalah di BPJS Ketenagakerjaan Cimahi sebagai pendukung keamanan data dan sebagai perusahaan penyedia jaminan sosial yang secara otomatis banyak melakukan korespondensi dengan berbagai perusahaan lain. Berikut adalah tabel jumlah surat masuk dan keluar di BPJS Ketenagakerjaan Cimahi:

Tabel 1.1

\section{SURAT KELUAR \& MASUK BPJS KETENAGAKERJAAN CIMAHI}

TAHUN 2018

\begin{tabular}{|c|c|c|}
\hline Bulan & Jumlah Surat Masuk & Jumlah Surat Keluar \\
\hline Januari- Desember & 1.191 & 8.646 \\
\hline Total & Surat Masuk \& Keluar & 9.837 \\
\hline
\end{tabular}

Sumber: BPJS Ketenagakerjaan Cimahi (2019)

Jumlah surat masuk dan keluar yang banyak membutuhkan pengelolaan pendistribusian dan penyimpanan data yang baik agar proses administrasi dalam organisasi dapat terus berjalan lancar. Berdasarkan hal itu, penelitian ini bertujuan untuk mendeskripsikan bagaimana proses pendistribusian surat masuk menggunakan aplikasi Dropbox di BPJS Ketenagakerjaan Cimahi dan bagaimana kelebihan dan kekurangan setelah pendistribusian surat masuk menggunakan aplikasi Dropdox di BPJS Ketenagakerjaan Cimahi. 


\section{Kajian Pustaka}

\section{Penanganan Surat Masuk}

Digitalisasi teknologi telah merubah tata cara berkorespondensi konvensional ke sistem otomatisasi perkantoran moderen dengan konsep paperless namun dalam implementasinya banyak organisasi khususnya instansi pemerintahan masih memerlukan bukti fisik dari surat. Korespondensi memiliki peran yang sangat penting dalam membangun komunikasi yang baik bagi suatu pihak kepada pihak lain khususnya dalam dunia perkantoran. Terbentuknya komunikasi yang baik akan membentuk hubungan yang baik antara instansi tersebut dengan pihak internal maupun eksternal. Oleh karena alasan tersebutlah maka setiap instansi perlu memiliki kemampuan berkorespondensi yang baik untuk membentuk hubungan baik dengan berbagai pihak. Priansa \& Garnida, 2013 menyatakan bahwa korespondensi adalah kegiatan berkomunikasi dengan menggunakan surat sedangkan Purwanto, 2014 menyatakan bahwa korespondensi merupakan salah satu bentuk komunikasi pesan-pesan bisnis maupun nonbisnis kepada pihak lain. Menurut Sedarmayanti,2014 bahwa korespondensi adalah salah satu bentuk komunikasi dengan mempergunakan surat sebagai alat komunikasi tertulis yang berasal dari satu pihak ditujukan kepada pihak lain untuk menyampaikan warta.

Berdasarkan jumlah penerimanya surat dapat dibedakan menjadi surat biasa, surat edaran, dan surat pengumuman (Asriel, 2018) sedangkan berdasarkan sifatnya surat dapat dikelompokan menjadi surat biasa, surat konfidensial (terbatas) dan surat rahasia. Setiap surat yang masuk dalam suatu organisasi harus dapat segera didiistribusikan agar pesan dari surat dapat segera tersampaikan. pengelolaan surat masuk yaitu penerimaan surat, penyortiran surat, pencatatan surat, pengarahan surat dan penyimpanan surat. Menurut Sedarmayanti (2015) proses penanganan surat masuk dapat dilakukan lebih sederhana sebagai berikut:

Tabel 2.1

PROSEDUR PENGELOLAN SURAT MASUK

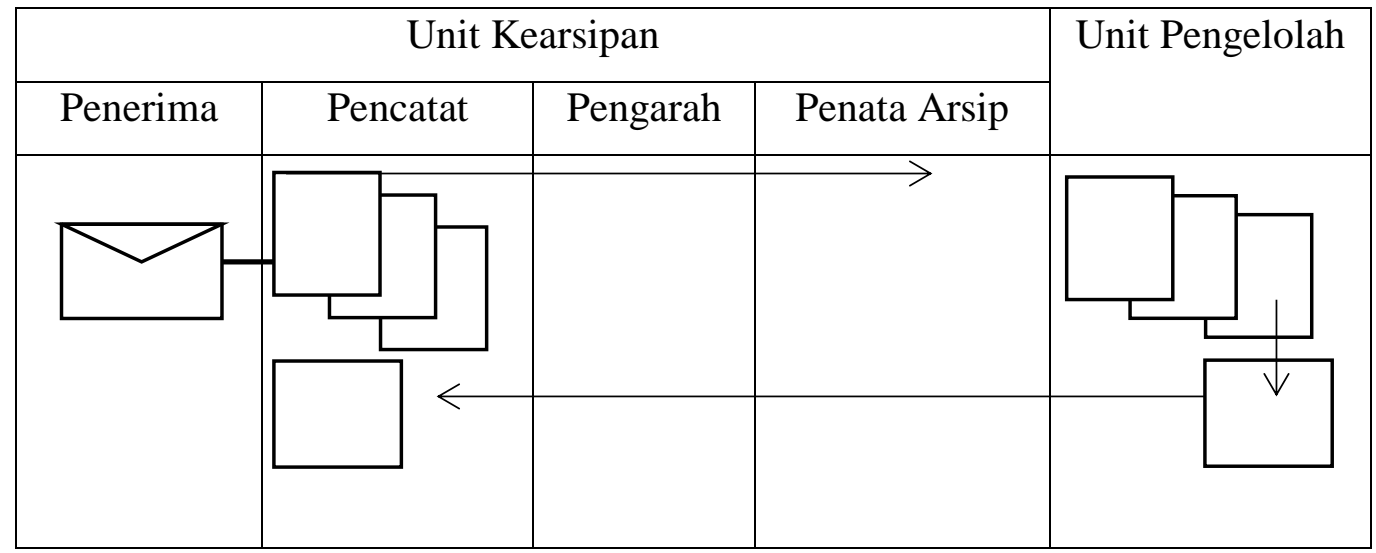


Seperti penjelasan pada tabel di atas bahwa proses pengelolaan surat masuk di mulai saat surat diterima oleh pihak organisaisi yang dituju, lalu surat tersebut diproses hingga akhirnya pihak organisaisi membalas surat tersebut.

\section{Komunikasi Internal}

Komunikasi internal menyediakan cara yang jelas untuk berkomunikasi dengan orang lain, sehingga mereka berbagi informasi tentang tujuan atau inisiatif sendiri, dan mencapai tujuan lebih cepat (Kline \& Ishii, 2008). Komunikasi internal merupakan fungsi komunikasi yang secara khusus dirancang oleh perusahaan untuk membangun dan membina hubungan dengan stakeholder internal, sehingga tercipta kedekatan emosional yang diwujudkan melalui komitmen dan keterlibatan yang bermanfaat bagi kesuksesan terkait pencapaian tujuan perusahaan (Wijaya, 2015)

Dalam komunikasi internal sering terjadi kesalahpahaman yang akan menghambat proses kerja dan menyebabkan keterlambatan pencapaian tujuan organisasi. Efektivitas komunikasi dapat terlihat dari kemampuan menggunakan media informasi yang digunakan dalam mempengaruhi kelompok sasaran sesuai dengan yang diinginkan.

\section{Dropbox}

Di era digital saat ini cloud computing menjadi suatu hal kebutuhan bagi organisasi maupun personal dimana informasi dapat dilakukan secara up date. Cloud storage adalah sebuah layanan penyimpanan data online yang disatukan dan disesuaikan secara online dan dapat diakses dengan berbagai jenis perangkat (Kurniawan et al., 2017). Cloud Storage dapat diartikan sebagai teknologi yang menggunakan jaringan komputer yang luas atau internet sebagai media dalam pengaksesan serta penyimpanan data - data digital tanpa harus terkendala oleh jarak (Heryana \& Putra, 2018). Cloud computing dapat menghilangkan kebutuhan untuk memelihara perangkat keras komputasi yang mahal, ruang khusus, dan perangkat lunak (Hashem et.el., 2014). data yang disimpan pada cloud storage akan dapat diakses dimana saja serta kapanpun. Cloud storage akan diintegrasikan ke berbagai perangkat untuk mendapatkan kemudahan pengaksesan seperti ke perangkat mobile (smartphone), tablet serta personal komputer, fitur unggulan lainnya yaitu tersedianya file sharing yang memudahkan untuk berbagi file dengan pihak lain (Oktafeearto et al., 2018).

Salah satu layanan penyimpanan cloud adalah Dropbox yang memberi pengguna cara yang nyaman dan andal untuk menyimpan dan berbagi data dari mana saja, di perangkat apa saja, dan kapan saja. Dropbox menggunakan dua cloud berbeda untuk menyimpan konten file dan metadata(Li et.al., 2019). Dropbox adalah layanan penyedia data berbasis web yang dioperasikan oleh Evenflow, 
Inc. Yang merupakan sistem penyimpanan berjaringan untuk menyimpan dan berbagi data serta berkas dengan pengguna lain di internet menggunakan sinkronisasi data. Dropbox juga merupakan salah satu penyedia layanan cloud storage yang cukup populer dan termasuk pemain lama dalam bidang ini. Untuk menggunakan layanan cloud storage Dropbox diperlukan install software yag disediakan oleh Dropbox di situsnya untuk dapat didownload gratis dan di install di Windows, Mac, maupun Linux. Setelah menginstall Dropbox, maka di komputer akan ada folder khusus milik Dropbox (Yulistyanti,2016). Dropbox adalah layanan penyimpanan cloud yang menyederhanakan file sharing, dropbox menyediakan entri data offline dan file online sinkronisasi(Yoldi-Negrete, et.al., 2018).

\section{Metode Penelitian}

Penelitian ini didasarkan pada tinjauan literatur yang komprehensif. Metode yang digunakan dalam penelitian ini adalah penelitian kualitatif dengan pendekatan deskriptif dan menjadikan BPJS Ketenagakerjaan Cimahi sebagai obyek dari penelitian dikarenakan BPJS sebagai salah satu perusahaan ini lingkup bisnisnya yang besar dan jumlah dari pelanggann dengan lalu lintas komunikasi melalui suratnya cukup tinggi.

\section{Hasil Penelitian dan Pembahasan}

BPJS adalah singkatan dari Badan Penyelenggara Jaminan Sosial. BPJS Ketenagakerjaan merupakan badan yang menyediakan jaminan perlindungan bagi tenaga kerja dengan sistem asuransi. Tingkat intensitas korespondensi di BPJS Ketenagakerjaan Cimahi cukup tinggi dengan berbagai kategori surat menyurat. BPJS Ketenagakerjaan Cimahi menyimpan sementara dan mendistribusikan suratnya dengan menggunakan sebuah aplikasi penyimpanan Dropbox yang mana hal tersebut merupakan sebuah inovasi dari sekretaris unit kerja cabang Cimahi.

Pengelolaan surat dilakukan oleh sekretaris dengan menggunakan aplikasi Dropbox di BPJS Ketenagakerjaan Cimahi dimulai dari tahap penerimaan surat hingga surat tersebut atau informasi dalam surat tersebut tersampaikan kepada unit pengolah yang telah ditunjuk oleh pejabat pimpinan dalam lembar disposisi.

Di BPJS Ketenagakerjaan Cimahi surat datang dari dua sumber yaitu dari kurir dan dari email yang masuk ke akun BPJS Ketenagakerjaan Cimahi. di BPJS ketenagakerjaan Cimahi jika surat datang dari kurir tugas pencatat yang dilakukan oleh sekretaris adalah harus menandatangani bukti tanda terima setelah menerima surat tersebut dan jika surat dikirim melalui email sekretaris akan mencetak 
surat tersebut kedalam bentuk hardcopy. Di BPJS Ketenagakerjaan Cimahi tidak penyimpan atau mengumpulkan surat lebih dari satu hari karena setiap surat yang datang akan langsung diproses pada hari surat itu diterima oleh sekretaris.

Pelaksanaan penyortiran harus dilakukan dan hal ini sesuai dengan yang diterapkan oleh BPJS Ketenagakerjaan Cimahi. Pada BPJS Ketenagakerjaan Cimahi semua surat disortir terlebih dahulu oleh sekretaris berdasarkan jenis surat yaitu menurut wujudnya, sifatnya dan jumlah penerimanya setelah surat diterima sekretaris akan memeriksa kebenaran alamat. Jika surat rahasia yang datang sekretaris membedakannya dari tanda hijau yang berada di amplop surat tersebut dan biasanya akan langsung didisposisikan kepada kepala cabang. Untuk surat biasa sekretaris akan mengelompokkan berdasarkan wujud, seperti undangan, nota, telegram dll atau berdasarkan jumlah penerima misalnya surat edaran, surat perintah dll. karena proses pencatatan surat sudah menggunakan teknologi, sekretaris akan mencatat tanggal penerimaan surat, nomor surat, tanggal pembuatan surat dan perihal dari surat masuk tersebut dalam spreadsheet, setelah surat diserahkan kepada pejabat pimpinan barulah sekretaris akan memproses surat tersebut untuk didistribusikan menggunakan aplikasi Dropbox. Penyimpanan surat dengan menyimpan softcopy surat dalam folder scanner pertahun selain juga fisik dari surat dan disposisi lembar ke dua akan digandakan dan disimpan untuk kebutuhan arsip dalam filling cabinet sekretaris selama setahun dengan sistem penyimpanan subjectical lalu setelah satu tahun surat-surat tersebut akan diserahkan pada bagian arsip dengan bersarkan sistem penyimpanan alphabetical dalam dua tempat yaitu di satu ruangan dalam kantor dan dalam tempat penyimpanan yang diberi nama rumah arsip.

Dengan beralihnya proses pendistribusian dari manual ke komputerisasi menggunakan aplikasi Dropbox mampu mendatangkan kemudahan dalam bekerja bagi sekretaris maupun bagi karyawan lain di BPJS Ketenagakerjaan Cimahi. Kelebihan pendistribusian surat mengunakan aplikasi dropbox yaitu 1) Dropbox sebagai cloud storage dapat diintergrasikan keberbagai perangkat contohnya computer dan smartphone;2)Surat yang telah di upload di dropbox dapat diakses kapan saja dan dimana saja oleh setiap bagian yang telah mendapat disposisi atau petunjuk dari pejabat pimpinan; 3 ) Tersedia file sharing yang dapat memudahkan ketika ada karyawan yang meminta ulang surat sehingga link penyimpanan surat dapat langsung di share ke karyawan yang bersangkutan. Adapun kekurangan dari Dropbox adalah tergantung pada jaringan internet dan hanya memfasilitasi layanan penyimpanan gratis sebesar dua giga byte saja, jika pengguna membutuhkan kapasitas yang lebih besar lagi Dropbox akan mengenakan sejumlah biaya. 
TABEL 4.1

ALUR SURAT MASUK

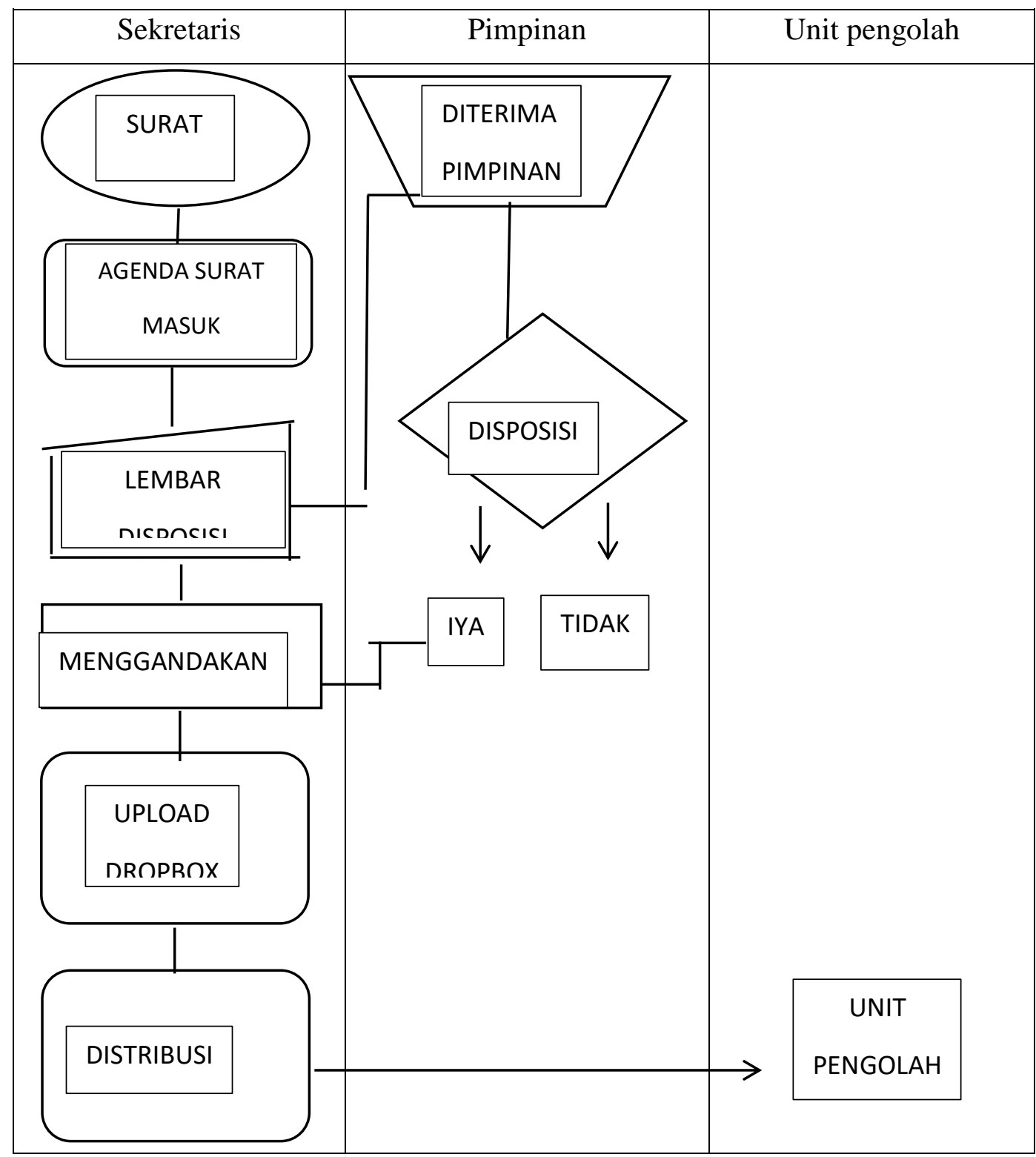

Sumber: BPJS Ketenagakerjaan Cimahi (2019) 


\section{Kesimpulan}

Di era digital saat ini perusahaan harus mulai beralih ke digitalisasi baik dalam layanan maupun komunikasi. Pesatnya perkembangan teknologi mendorong perusahaan melakukan transformasi di bidang teknologi salah satunya di dalam proses administrasi diantaranya penggunaan aplikasi berbasis cloud computing. Salah satu jenis penyimpanan berkas dengan layanan cloud storage adalah Dropbox.

Aplikasi Dropbox ini dapat membantu kerja karyawan menciptakan kerja sama yang baik bagi sesama karyawan maupun karyawan dengan pimpinan sehingga komunikasi internal berjalan lancar dan tujuan perusahaan dapat tercapai. Selain itu juga kelebihan-kelebihan yang didapatkan dari penggunaan Dropbox dapat mempermudah kerja karyawan sehingga pekerjaan dapat diselesaikan tepat waktu,

\section{Saran}

Implementasi penggunan aplikasi Dropbox dapat ditingkatkan menjadi tempat penyimpanan surat-surat secara permanen dengan meningkatkan kapasitas ke berbayar sehingga optimalisai layanan dan komunikasi internal dapat lebih baik dan mempercepat pencapaian tujuan perusahaan. Namun tingkat keamanan perlu diperhatikan dalam pemberian wewenang pembukaan file di Dropbox untuk menjaga kerahasian dari file perusahaan tersebut. 


\section{Daftar Pustaka}

Asriel, Armida Silvia. 2018. Manajemen Kearsipan.Bandung: PT Remaja Rosdakarya.

Barthos, Basir. 2009. Manajemen Kearsipan. Jakarta: Bumi Aksara

Boudewijn de Bruin dan Luciano Floridi. 2017. The Ethics of Cloud Computing. [Online] Tersedia: https://link. springer.com/article/10.1007/s11948-016-9759-0.

Caviglione et.al., 2016. The Dropbox Tour. Available at https://www.dropbox.com/tour/0 (last accessed Januari 14, 2020).

Hashem et.el., 2014. The riseof "big data" on cloud computing: Review and open researchissues

Heryana dan Putra. 2018. Perancangan Dan Implementasi Infrastruktur Jaringan Komputer Serta Cloud Strorage Server Berbasis Kendali Jarak Jauh (Studi Kasus Di Pt. Lapi Itb) [Online]. Tersedia: http://jurnal.unnur.ac.id/index.php/jurnalfiki/article/view/240/204.

Kline, S.L. dan Ishii, D. K. (2008). Procedural Explanations in Mathematics Writing: A Framework for Understanding College Students' Effective Communication Practices. Written Communication. 25(4): 441-461.

Kurniawan et al., 2017. Implementasi Algoritma AES dalam Mengenkripsi Berkas Terintegrasi dengan Layanan Cloud Storage Berbasis Android. [Online] Tersedia: http://seminar.iaii.or.id/index.php/SISFOTEK/article/view/84/73.

Li et.al., 2019. A Quantitative and Comparative Study of Network-Level Efficiency for Cloud Storage Services. ACM Trans. Model. Perform. Eval. Comput. Syst., Vol. 4, No. 1, Article 3. Publication date: January 2019

Listiyarini, Ratih. 2019. Siap UN/ USBN Elektronika SMK. Ponorogo: Uwais Inspirasi Indonesia. Oktafeearto et al.,. 2018. Rancang Bangun Server Cloud Storage Mahasiswa Dan Dosen Menggunakan Owncloud Pada Jaringan Lokal Di Kampus Stmik Dumai. [Online], Vol 10, 27 Halaman. Tersedia: http://www.ejournal.stmikdumai.ac.id/index.php/path/article/view/112/50. [18 April 2019].

Priansa, Doni Juni dan Agus Garnida. 2013. Manajemen Perkantoran. Bandung: Alfabeta, CV

Radu, Ana Maria dan Zdzislaw Polkowski.2014. Theoretical, technical and practical aspects of eadministration. [Online], Tersedia: https://www.researchgate.net/publication/261712638.

Sambamurthy, V., Bharadwaj, A., \& Grover, V. (2003). Shaping Agility Through Digital Options: Reconceptualizing The Role Of Information Technology In Contemporary Firms. Mis Quarterly, 27(2), 237-63

Sedarmayanti, 2014. Tugas Dan Pengembangan Sekretaris Profesional Untuk Meraih Keberhasilan. Bandung: CV. Mandar Maju.

Sedarmayanti. 2015. Tata Kearsipan. Bandung: CV. Mandar Maju.

Suryana, Taryana, 2012. Pengelolaan Dokumen Sebagai Sarana Komunikasi Internal Unikom. Jurnal Komputer dan Informatika (KOMPUTA), Edisi. I Volume. 1, Maret 2012

Wijaya, 2015. Strategi Komunikasi Internal Pt X Dalam Membina Employee Engagement. Jurnal E--Komunikasi Vol 3. No.1 Tahun 2015.

Wijaya, Filemon,2015. Strategi Komunikasi Internal Pt X Dalam Membina Employee Engagement. Jurnal E-Komunikasi Vol 3. No.1 Tahun 2015.

Yoldi-Negrete, et.al., 2018. Combining Adobe Forms and Dropbox to Obtain a Low-Cost Electronic Data Collection System. DOI: 10.1089/tmj.2018.002 


\section{Referensi}

Abubakar, H. (2012). Pola Kearsipan Modern. Jakarta: Djambatan

Aslizadeh. (2014). Indian Journal of Fundamental and Applies Life Sciences ISSN: 2231-6345 (online) Vol. 4 (S4), pp. 1595-1603/Research Article 2-14/Centre for Info Bio Technology (CIBTech) 1595 Impact of Using Information Technology on Creating a Sustainable Competitive Advantage for Companies (Case Study: Golestan Food Companies).

Ferreira. (2011). SMEs and E-Business: Implementation. Strategies and Policy (page 1-22).

Haryadi. (2009). Administrasi Perkantoran untuk Manajemen dan Staf. Jakarta: Transmedia Pustaka.

Migdadi, M.M et al. (2015). An Empirical Assessment of the Antecedents of Electronic-Business Implementation and the Resulting Organizational Performance (page 661-688).

Muhidin, A.S. (2016). Pengelolaan Arsip Digital (hal. 178-183). Jurnal Pendidikan Bisnis dan Manajemen, Vol 2(3).

Priansa. D.J. 2013. Kesekretarisan Profesional. Bandung: Alfabeta.

Putranto, A.W. (2017). Pengelolaan Arsip di Era Digital (hal 1-11).

Rifauddin, Machsun. (2016). Pengelolaan Arsip Elektronik Berbasis Teknologi (hal 168-178). Khizanah Al Hikmah Jurnal Ilmu Perpustakaan, Informasi, dan Kearsipan.

Nur dan Nani. (2017). Penerapan Sistem Kearsipan Elektronik sebagai Determinan terhadap Produktivitas Kerja Pegawai. Jurnal Pendidikan Manajemen Perkantoran, Vol. 2 (2), hal 4048.

Sugiarto, A. (2015). Manajemen Kearsipan Modern. Yogya : Gava Media.

Sugiyono. (2013). Metode Penelitian Pendidikan Pendekatan Kuantitatif, Kualitatif, dan $R \& D$. Bandung: Alfabeta.

Sugiyono. (2015). Metode Penelitian Kombinasi (Mix Methods). Bandung: Alfabeta

Sugiyono. (2016). Metode Penelitian Kuantitatif, Kualitatif, dan R\&D. Bandung: Alfabeta.

Tung, H., et al. (2011). Conservation of Information and E-Business Success and Challenges: A Case Study (hal. 254-269). 